\title{
PERILAKU PASANGAN USIA SUBUR DALAM KEPESERTAAN AKSEPTOR KELUARGA BERENCANA DI MASYARAKAT BADUY
}

\author{
Omo Sutomo \\ Jurusan Kebidanan Poltekkes Kemenkes Banten \\ Korespondensi: omo_sutomo@poltekkesbanten.ac.id
}

\begin{abstract}
Family Planning Program has a large contribution of efforts to reduce the rate of maternal mortality, because Family planning program will directly reduce the "rate" of women who are pregnant and giving birth, and also contribute to the "ratio" of maternal mortality. Data or information related to the use of contraceptives by reproductive age couples in Baduy communities located in Lebak district with unique cultural characteristics are still closed in many ways including in terms of health and family planning program has not been well identified. This study aims to obtain in-depth information about the behavior of couples in reproductive age in participation of being as an acceptors in family planning program in the Baduy community. The design of this study is qualitative research. In order to obtain the necessary information, in-depth interviews were conducted with six key informants, and ten informants which are the mothers in the category of fertile age couples in the Baduy tribe region. The collected data is processed and then analyzed by using content analysis. The results showed that a lot of mothers were not using contraception, informants' knowledge about contaception was still very limited/low. To obtain contraceptive services, mothers use Posyandu in almost all villages. Most types of contraception used by reproductive age couple are contraceptive injections. The village government supports the efforts of family planning programs in the Baduy region, by providing support in the form of providing posyandu sites and cadres in assisting Posyandu activities. Cisimet Community Health Center should improve health promotion in the form of health education / health counseling which in accordance with community conditions and involves community leaders and "Jaro" or village heads in care related to health and family planning efforts, so that informants gradually have knowledge, attitudes and behavior to receive family planning programs according to their needs.
\end{abstract}

Keyword : Acceptors, Baduy Community

\begin{abstract}
ABSTRAK
Keluarga Berencana mempunyai kontribusi yang besar terhadap upaya penurunan angka kemantian ibu melahirkan, karena keluarga berencana secara langsung akan menurunkan "rate" wanita yang hamil dan melahirkan, dan sekaligus juga berkontribusi terhadap "ratio" kematian ibu. Data atau informasi yang berkaitan dengan penggunaan alat kontrasepsi oleh Pasangan Usia Subur di masyarakat Baduy yang berlokasi di kabupaten Lebak dengan karakteristik budaya yang unik dan masih tertutup dalam banyak hal termasuk dalam hal kesehatan dan keluarga berencana belum teridentifikasi dengan baik. Penelitian ini bertujuan untuk memperoleh informasi secara mendalam tentang perilaku pasangan usia subur dalam kepesertaan sebagai akseptor keluarga berencana di masyarakat Baduy. Desain penelitian ini adalah peneltian kualitatif. Untuk memperoleh informasi yang diperlukan dilakukan wawancara mendalam terhadap enam orang informan kunci, dan sepuluh orang informan
\end{abstract}


yakni ibu-ibu dalam katagori pasangan usia subur di wilayah suku Baduy. Data yang terkumpul diolah kemudian dilakukan analisis isi atau content analysis. Hasil penelitian menunjukkan bahwa masih ditemukan ibu-ibu belum menjadi akseptor $\mathrm{KB}$, pengetahuan informan tentang keluarga berencana masih sangat terbatas/rendah. Untuk memperoleh pelayanan kontrasepsi ibu-ibu memanfaatkan posyandu yang berada di hampir semua kampung. Jenis alat kontrasepsi yang digunakan sebagian besar pasangan usia subur mengunakan suntik. Pemerintah desa mendukung upaya program keluarga berencana di wilayah Baduy, dengan memberikan dukungan berupa penyedian tempat posyandu dan kader dalam membantu kegiatan posyandu. Kepada Puskesmas Cisimet perlu kiranya meningkatkan promosi kesehatan berupa pendidikan kesehatan/penyuluhan kesehatan yang dalam pelaksanaannya disesuaikan dengan kondisi masyarakat dan melibatkan para tokoh masyarakat dan "Jaro" atau kepala desa dalam kagiatan yang berkaitan dengan upaya kesehatan dan keluarga berencana, sehingga informan secara bertahap memiliki pengetahuan, sikap dan perilaku untuk menerima program keluarga berencana sesuai kebutuhannya

\section{Kata Kunci : Akseptor Keluarga Berencana, Masyarakat Baduy}

\section{PENDAHULUAN}

Pembangunan

kesehatan yang

dilaksanakan selama ini telah berhasil meningkatkan derajat kesehatan masyarakat yang cukup bermakna, namun demikian tidak dipungkiri bahwa masih juga dijumpai berbagai masalah dan hambatan, sehingga pencapaian program belum maksimal. Salah satu indikator yang paling peka untuk mengukur derajat kesehatan masyarakat adalah angka kematian ibu melahirkan disampaing angka kematian bayi. Kematian ibu melahirkan pada umumnya disebabkan oleh perdarahan, infeksi dan keracunan kehamilan dalam masa reproduksi. Salah satu upaya yang memiliki kontribusi yang besar terhadap upaya penurunan angka kematian ibu melahirkan adalah keikutsertaan pasangan usia subur dalam program Keluarga Berencana $(\mathrm{KB})$, karena KB secara langsung akan menurunkan "rate" wanita yang hamil dan melahirkan, dan sekaligus juga berkontribusi terhadap penurunan "ratio" kematian ibu untuk menjawab permasalahan "empat terlalu", yakni terlalu tua, terlalu muda, terlalu sering, terlalu dekat (Bapenas, 2009).

Saat ini intensitas program KB masih perlu ditingkatkan baik ditingkat pusat maupun daerah. Data atau informasi yang berkaitan dengan kepesertaan PUS dalam penggunaan alat kontrasepsi di masyarakat Baduy kabupaten Lebak belum teridentifikasi dengan baik. Perilaku kesehatan termasuk dalam hal ber-KB dipengaruhi oleh tiga faktor (Green, 1980), faktor tersebut yaitu faktor predisposing seperti pengetahuan, sikap, nilai, factor pemungkin seperti ketersediaan sarana dan prasarana dan faktor pendorong seperti dukungan tokoh masyarakat dan pejabat 
publik lainnya. Masyarakat Baduy merupakan salah satu suku yang berada di kabupaten Lebak merupakan masyarakat yang unik. Hasil pengamatan lapangan menunjukkan bahwa masyarakat Baduy yang memiliki budaya yang unik dan masih tertutup dalam banyak hal termasuk bidang kesehatan dan keluarga berencana, menunjukkan bahwa data atau informasi yang berkaitan perilaku keiikutsertaan PUS dalam penggunaan alat kontrasepi tidak terdokumentasi dan terinformasikan secara baik, sehingga informasi secara utuh belum diketahui. Kondisi ini dapat mengganggu pengambilan keputusan dalam hal peningkatan kesehatan reproduki PUS di masyarakat Baduy. Karena itu perlu dilakukan kajian terkait dengan kepesertaan PUS dalam program $\mathrm{KB}$, yang hasilnya dapat digunakan sebagai masukan penyusunan perencanan atau kebijakan peningkatan kesehatan ibu.

\section{METODE}

Penelitian ini merupakan penelitian kualitatif, dengan sumber informasi terdiri dari enam orang informan kunci dan sepuluh orang informan. Informan kunci terdiri dari kepala puskesmas, penanggung jawab KIA dan KB, kepala desa (jaro) dan tokoh masyakat (olot). Sementara yang menjadi informan ialah pasangan usia subur (suami istri) yang berada di wilayah suku Baduy
Cisimet kabupaten Lebak. Pengumpulan data dilakukan dengan menggunakan pedoman wawancara mendalam terhadap informan kunci dan informan terpilih. Semua data dari sumber informasi dicatat dalam catatan lapangan (field notes) dan direkam dengan menggunakan tape recorder. Data yang terkumpul diolah dan selanjutnya dilakukan analisis isi atau content analysis.

\section{HASIL DAN PEMBAHASAN}

\section{Sosiodemografi Sumber Informasi (Informan)}

Umur informan bervariasi antara 18 sampai dengan 33 tahun, Sementara informan kunci berumur 43 tahun dan tertua berumur 62 tahun. Ini menunjukkan bahwa informan termasuk dalam usia reproduksi sehat dan mereka memerlukan bantuan seperti penyuluhan, bimbingan agar lestari sebagai peserta KB. Sementara para informan kunci khususnya kepada desa dan tokoh masyarakat dengan umur yang dalam katagori dewasa dan tua diharapkan dengan ketokohannya dapat mempengaruhi para PUS untuk menjadi akseptor KB, diperlukan pendekatan khusus terhadap para tokoh masyarakat mengingat keunikan masyarakat Baduy.

Seluruh informan tidak memiliki pekerjaan tetap, kalaupun ada mereka umumnya bekerja sambilan yakni menenun 
kain yang dilakukan di rumah. Informan (ibu-ibu) tidak bekerja, mereka hanya bekerja sampingan sebagai penenun. Suami mereka biasanya bekerja berkebun. Dengan menenun mereka akan mendapat penghasilan yang dapat digunakan untuk membantu pendapat keluarga.

Jumlah anggota keluarga bervariasi antara dua sampai lima orang, sebagian besar informan mempunyai anak dua oang, sementara informan kunci sebagian besar tiga orang. Dilihat dari jumlah anggota keluarga menunjukkan bahwa para informan sebagian besar dalam katagori keluarga yang ideal. Jumlah anak atau anggota keluarga ideal ini penting untuk dipertahankan agar keluarga dapat memelihara/merawat anggota keluarga dengan baik.

\section{Perilaku PUS dalam Kepesertaan Akseptor KB.}

Hasil penelitian memperlihatkan bahwa masih ditemukan ibu-ibu atau PUS belum menjadi akseptor $\mathrm{KB}$, dengan alasan belum mendapat persetujuan/ijin dari suami dan alasan adat istiadat.

"heunteu kami mah, ari eta nu lain meren make, henteu kami mah ... (tidak saya tidak, barangkali yang lain menggunakan, saya tidak ...)

"Kami mah kie bae, henteu make KB" ... can menang ... teu menang $k u$ bapana ... salaki kami ...ku adat (kami begini saja, tidak menggunakan KB ... belum mendapat persetujuan dari suami ....adat )
Sementara itu ibu-ibu yang menjadi perserta KB, sebagian besar menjadi akseptor karena kemauan sendiri, dan jenis kontrasepsi metode suntik dengan alasan lebih praktis. Mereka tertarik menjadi akseptor setelah mendapatkan penyuluhan dari bidan dan kader Posyandu.

“ Kami mah make suntik...., pan eta bu bidan sok penyuluhan .... kader di Posyandu (saya pakai suntik ..., itu ibu bidan memberikan penyuluhan, kader juga di Posyandu)

“... make suntik mah gampang, teu ribet, aya nu sabulan, tilu bulan, kumaha hayangna bae ... (pakai KB suntik, mudah, tidak sulit, ada yang satu bulan, tiga bulan sekali tergantung keinginan)

Adapun tempat memperoleh pelayanan KB, mereka mendapat pelayanan di Puskesmas, Posyandu. Bidan yang melayani menurut mereka sangat baik, dan tidak menbayar, kecuali di tempat bidan mereka membayar.

“... ari eta mun disuntik ulang, atawa rek mimiti, eta sok ka posyandu, puskemas, sakali-kali ka bidan sakalian dipariksa, bisi aya naon-naon ... ayena mah teu bayar kami mah ... tah lamun ka bidan etamah bayar pan di imah na ...(kalau mau suntik ulang atau baru ke Posyandu, Puskesmas sekalian, sekali-kali ke bidan sekalian diperiksa khawatir ada apa-apa.. sekarang kami tidak bayar ... kecuali di tempat praktek bidan di rumahnya)

Menurut PUS (yang menjadi akseptor $\mathrm{KB})$, selama ini tidak menemukan hambatan yang berarti untuk memperoleh layanan KB. Namun ketika ditanyakan lebih khusus suka pusing, ada yang bertambah berat badannya. 
"Salila ayeuna mah teu naon-naon ... lancer bae ...iyeu bagus supaya urang sarehat ... teruskeun bae ... anu ayeuna geus bagus diteruskeun bae ...penyuluhanana... pelayanana, teu bayar diteuruskeun .. hee ..hee

(selama ini tidak ada apa apa, baik-baik saja, .... ini baik agar kita sehat, teruskan saja, sekarang sudah baik teruskan penyuluhan, pelayanan, tidak bayar hee ..hee).

"paling geh sok nyeri hulu ... puyeng, aya nu nambah beratna hee ... jadi gendut ... hee hee (sekedar sakit kepala, pusing, ada yang bertambah berat badannya, jadi obesitas, hee ... hee, ketawa).

Tidak satupun metode kontrasepsi yang aman dan efektif bagi semua klien, karena masing-masing mempunyai kesesuaian dan kecocokan individual bagi setiap klien (Safiuddin, 2008). Dengan kata lain penggunaan metode metode $\mathrm{KB}$ harus disesuaikan dengan kebutuhan dan indikasi pasien yang ingin memilihnya.

Namun secara umum persyaratan metode kontrasepsi ideal mencakup hal-hal sebagai berikut ; 1) aman, artinya tidak akan menimbulkan komplikasi berat bilan digunakan, 2) berdayaguna, dalam arti bila digunakan sesuai dengan aturan akan dapat mencegah terjadinya kehamilan, 3) dapat diterima, bikan hanya oleh klien melainkan juga oleh lingkungan budaya di masyarakat, 4) terjangkau harganya oleh masyarakat, 5) bila metode tersebut dihentikan pengunaannya, klien akan segera kembali kesuburanya, kecuali untuk kontrasepsi mantap.

Dengan keikutsertaan ibu-ibu sebagai akseptor KB dengan metoda hormonal (suntik), menunjukkan bahwa ibu-ibu sudah memperlihatkan tumbuhnya kesadaran pentingnya $\mathrm{KB}$ bagi mereka, meskipun memang perlunya penyuluhan kesehatan dan pendekatan yang lebih intensif dari petugas kesehatan (bidan) terhadap PUS yang belum menjadi akseptor $\mathrm{KB}$ agar terdorong dan mau menjadi akseptor $\mathrm{KB}$, sehingga diadakannya gerakan keluarga berencana sebagaimana dikemukakan oleh Suratun, etal (2008) bertujuan antara lain mencegah terjadinya ledakan penduduk dengan menekan laju pertumbuhan pendudukan, dengan demikian tujuan akhir dari gerakan keluarga berencana yakni tercapainya Norma Keluarga Kecil Bahagia dan Sejahtera (NKKBS) dan membentuk keluarga yang berkualitas yakni suatu keluarga yang harmonis, sehat, tercukupu sandang, pangan, papan, pendidikan dan produktifitas dari segi ekonomi dapat tercapai.

Skinner dalam Notoatmodjo (2010), mengemukakan bahwa perilaku merupakan hasil hubungan antara perangsang (stimulus) dan respon. Dalam kaitan dengan perilaku PUS dalam kepesertaan sebagai akseptor KB terdapat kemungkinan karena adanya rangsangan berupa penyuluhan, nasihat yang 
diberikan oleh bidan dan kader di posyandu serta pelayanan yang baik oleh bidan, hal ini yang selanjutnya ibu-ibu tertarik ikut menjadi akseptor, disamping peranan tokoh masyarakat (olot) dan perangkat desa/kepala desa (jaro) yang tidak mempersoalkan program KB.

\section{Pengetahuan PUS tentang KB}

Pengetahuan informan tentang keluarga berencana masih sangat terbatas/rendah. mereka hanya tahu bahwa KB itu hanya untuk menunda atau menjarangkan kelahiran belum melihat bahwa KB merupakan bagian dari upaya untuk kesehatan dan kesejahteraan masyarakat. Yang mereka ketahui jenis kontrasepsi adalah pil, suntik dan alat IUD/AKDR (alat kontrasepsi dalam rahim). Hampir seluruh ibu-ibu tidak mengetahui secara rinci ibu-ibu yang boleh dan tidak boleh menggunakan kotrasepsi, yang mereka tahu ibunya supaya sehat, dalam artian umum, seperti tidak sakit, seperti yang diungkapkan salah satu informan :

"ceuk kami mah, KB mah sangkan urang bisa ngajarangkeun ngalahirkeun ktu meren heh .. heh (menurut saya, KB itu supaya dapat menjarangkan kelahiran, itu barangkali heh ..heh)"

“ Naon bae nya ... eta pil, suntik, jeung IUD, eta nya pa..." (apa yah .. itu pil, suntik, IUD, itu ya pak)

"Teu nyaho kami mah, pokok na ayeuna kami keur sehat teu gearing, bisa jadi akseptor $K B$, nu lain mah teu nyaho ..." (Tidak tahu, pokoknyasekarang kami sedang sehat, tidak sakit boleh menjadi akseptor $\mathrm{KB}$, yang lain tidak tahu ...)

Manuaba dalam Suratun (2008), mengemukakan bahwa metode kontrasepsi dapat digunakan oleh PUS secara rasional berdasarkan fase-fase kebutuhan, yakni pada masa menunda kesuburan/kehamilan, masa mengatur/menjarangkan kelahiran, dan masa mengakhiri kesuburan/tidak hamil lagi. Pada masalmenunda kehamilan pertama, sebaiknya dilakukan oleh pasangan yang istrinya belum mencapai usia 20 tahun, kontrasepsi yang cocok dan disarankan ialah pil, AKDR, kondom, vaginal jelly. Pada masa mengatur/menjarangkan kelahiran yaitu ibu berumur 20-30 tahun, yang cocok dan disarankan ialah AKDR, sunti, pil atau implant. Sedangkan pada masa mengakhiri/tidak hamil lagi dimana keluarga setelah mempunyai dua anak dan umur istri lebih dari 30 tahun, yang cocok dan disarankan adalah metode kontap, AKDR, implant, suntik dan pil.

Ibu-ibu/PUS memiliki pengetahuan yang sangat terbatas/rendah tentang $\mathrm{KB}$, rendahnya pengetahuan ibu-ibu tentang $\mathrm{KB}$, terdapat kemungkinan karena berkaitan dengan kesempatan berpendikan yang terbatas, yakni seluruh ibu-ibu yang menjadi informan dalam penelitian ini tidak berpendidikan formal, sehingga ibu-ibu 
sangat terbatas memperoleh informasi dan pemahaman yang memadai tentang KB.

\section{Ketersediaan dan Keterjangkauan}

\section{Sarana Pelayanan KB.}

Seluruh informan menyatakan bahwa di kampung mereka tidak ada sarana kesehatan seperti Puskesmas dan Poskesdes, yang ada hanya posyandu di tiap kampung, melayani pelayanan kontrasepsi disamping melayani penimbangan bayi/balita, imunisasi bayi dan ibu hamil, penyuluhan dan pemeriksaan ibu hamil. Sebagian besar informan menyatakan bahwa meskipun tidak ada puskesmas, yang menurut mereka letaknya tidak jauh dari kampung mereka. Masyarakat Baduy sudah terbiasa berjalan kaki kalau mau ke puskesmas untuk keperluan kesehatan, karena adat Baduy melarang menggunakan kendaraan untuk keperluan sehari-hari terutama di daerah Baduy, sehingga tidak akan ditemukan kendaraan bermotor beroperasi di wilayah Baduy.

Menurut mereka petugas kesehatan khususnya bidan yang bertugas melayani layanan kontrasepsi ada setiap hari, bersikap baik dan ramah melayani peserta akseptor, demikian pula layanan di posyandu setiap bulan menunjukkan sikap yang sama. Sepengatahuan mereka yang sering dan dekat dengan akseptor selama ini adalah bidan, sementara petugas selain bidan (non kesehatan) tidak ada.

"Kami mah mun rek diulang suntikan di posyandu bae di kampung dieu, deukeut tuh di ditu, .... Lamun di dieu di posyandu bulanan bukana, lamun di puskesmas mah sok buka tiap poe ... ka dituna lempang bae ... ja euweuh kandaraan jiga di kota mah loba:" (kami kalau mau suntik ulang di posyandu di kampung ini, itu dekat di situ... kalau disini posyandu bukanya setiap bulan, kalau di puskesmas tiap hari, ke sananya jalan kaki, karena tidak ada kendaraan , di kota banyak)

Di perkampungan Baduy tidak ditemukan saranan kesehatan seperti Puskesma, yang ada hanya posyandu di beberapa kampung yang beroperasi setiap bulan. Di posyandu inilah ibu-ibu mendapatkan pelayanan alat kontasepsi. Puskesmas adalah suatu unit pelaksana fungsional yang berfungsi sebagai pusat pembangunan kesehatan, pusat pembinaan peran serta masyarakat dalam bidang kesehatan serta pusat pelayanan kesehatan tingkat pertama yang minimal melaksanakan enam program pelayanan kesehatan dasar,yaitu 1) promosi kesehatan, 2) kesehatan ibu dan anak serta keluarga berencana, 3) gizi, 4) kesehatan lingkungan, 5) pencegahan dan penanggulangan penyakit menular dan 6) pengobatan. Ketersediaan sarana dan prasarana serta keterjangkauan memiliki nilai penting dalam upaya perubahan perilaku seseorang yang dalam hal ini perilaku sebagai peserta akseptor KB. 
Green (1980), menjelaskan lebih lanjut bahwa perilaku seseorang dipengaruhi oleh tiga factor yakni factor predisposing, factor enabling (pemungkin) dan factor reinforcing (pendorong). Dalam hal ketersediaan posyandu sebagai tempat memperoleh pelayanan KB bagi masyarakat Baduy merupakan faktor pemungkin atau pendukung bagi ibu-ibu mau menjadi akseptor KB.

\section{Dukungan Sosial.}

Ketika ditanyakan ke informan apakah ada dukungan pemerintah terhadap program KB pada masyarakat Baduy, dan apa kegiatan dukungan tersebut. Sebagian besar informan menyatakan bahwa yang mereka ketahui, khususnya dari Puskesmas sudah banyak membantu dalam upaya peningkatak layanan kesehatan termasuk pelayanan KB, bidan khususnya sebagai Pembina desa memberikan pelayanan $\mathrm{KB}$ di posyandu di kampung-kampung yang dalam pelaksanaannya dibantu oleh kader posyandu.

“ Sakumaha ayena eta puskesmas, bidan di posyandu panimbangan, imunisasi, sakalian mere panyuluhan, palayanan $n u \mathrm{~KB}$, .... Bu bidan kaliling ka tiap panimbangan tiap bulan sakalian nagalayanan KB" (seperti sekarang ini puskesmas, bidan di posyandu melakukan penimbangan, imunisasi, sekalian memberikan penyuluhan, melayani $\mathrm{KB}, \ldots$ bu bidan keliling ke tiap penimbangan setiap bulan sekalian melayani akseptor KB).
Pertanyaan yang sama ditujukan ke kepala desa ("Jaro"), menurut "Jaro" bahwa selama ini program puskesmas dalam memberikan pelayanan kesehatan sudah banyak membantu masyarakat Baduy, denikian pula pelayanan $\mathrm{KB}$, dengan ditempatkannya para bidan di tiap desa. Selama ini perangkat desa mendukung program kesehatan yang dijalankan oleh puskesmas, sebagaimana diungkapkan sebagai berikut :

"Didie mah, di desa kami, selama eta baek untuk masyarakat, ngadukung kana eta pamarentah, di kami aya posyandu diusahakan tiap kampung, eta salah sahiji dukungan kami kana program kasehatan, kami nayadiakeun tempat jeung masyarakat nu jadi kader, ari eta patugasna bidan ti puskesmas ..." (di sini di desa kami, selama itu baik untuk masyarakat, mendukung pemerintah, disini ada posyandu diupayakan di tiap kampung, itu salah satu dukungan kami terhadap program kesehatan, kami menyediakan tempat dengan masyarakat yang jadi kader, sementara petugasnya bidan dari puskesmas).

Sebagian besar informan menyatakan bahwa selama ini tidak ada hambatan yang berarti untuk memperoleh pelayanan kontrasepsi/KB.

“ Salila ayena mah lancer-lancar bae, ... ja lamun kami rek disuntik di posyandu bae, .... pan bidan sakalian panimbangan, imunisasi di posyandu" (selama ini lancar-lancar saja/tidak ada hambatan, jika aka di suntik, tempatnya di posyandu, ... ada bidan yang 
melayani sekalian penimbangan, imunisasi di posyandu)

Dukungan yang diberikan oleh perangkat desa/kepala desa/jaro, menunjukkan bahwa tingkat partisipasi atau dukungan sosial yang positif terhadap upaya kesehatan termasuk dalam gerakan KB. Hal ini sejalan dengan pendapat Pendit (2006) bahwa anggota atau kelompok dalam masyarakat termasuk dokter, pemimpin agaram, ahli farmasi, kelompok wanita, dan pemimpin lokal dapat memiliki dampak berarti pada aksesibilitas dan akseptabilitas berbagai metode kontrasepsi. Dukungan positif yang diberikan dimungkinkan sebagai respon terhadap keberadaan puskesmas dan bidan serta posyandu yang sudah membantu masyarakat dalam memberikan pelayanan kesehatan dan KB.

Sebagian besar ibu-ibu peserta KB, tidak menemukan hambatan/masalah yang berarti. Mereka memperoleh layanan kontrasepsi umumnya di posyandu yang dilayani oleh bidan. Hal ini menunjukkan bahwa pelayanan yang diberikan petugas kesehatan (bidan) sudah memenuhi kebutuhan yang diharapkan oleh akseptor. Keberadaan posyandu merupakan bukti bahwa mereka sangat mudah memperoleh layanan KB, yang bersamaan pelayanaanya dengan kegiatan penimbangan bayi/balita di posyandu setiap bulan.

\section{SIMPULAN}

1. Sosiodemografi menujukkan bahwa Informan termasuk dalam usia reproduksi sehat, termuda berumur 18 tahun an tertua 33 tahun, sementara informan kunci termuda berumur 45 tahun dan tertua 63 tahun. Seluruh informan tidak memiliki pekerjaan tetap, dan sebagian besar informan mempunyai dua orang anak, dan informan kunci 3 orang anak.

2. Masih ditemukan informan (PUS/ibu-ibu) yang belum menjadi akseptor $\mathrm{KB}$, hal ini karena belum mendapat persetujuan/ijin suami disamping masalah adar istiadat.

3. Pengetahuan informan tentang keluarga berancana masih sangat terbatas/rendah

4. Di perkampungan Baduy tidak terdapat sarana kesehatan seperti Puskesmas dan Poskesdes, yang ada hanya UKBM berupa posyandu.

5. Dukungan sosial yang diberikan oleh pemerintahan desa dalam pelaksanaan program KB adalah dengan menyediakan tempat untuk kegiatan posyandu dan kader dalam membantu kegiatan posyandu setiap bulan.

\section{DAFTAR PUSTAKA}

Green L.W, etal. 1980, Health Education Planning A Diagnosis Aprroach, California : Mayfield Publishing Company 
Kementerian Negara Perencanaan

Pembangunan Nasional/Badan

Perencanaan Pembangunan Nasional, 2009, Pembangunan Kesehatan dan

Gizi di Indonesia : Overview dan Arah ke Depan-Background Study RPJMN 2010-2014

Kemenkes RI, 2015, Rencana Strategis Kementerian Kesehatan 2015-2019, Jakarta : Kemenkes RI.

Saifuddin, A.B, etal. 2008, Pelayanan Kontrasepsi, Jakarta : Yayasan Bina Pustaka Sarwono Prawirahardjo

Suratun, etal. 2008, Pelayanan Keluarga Berencana dan Pelayanan Kontrasepsi, Jakarta : Trans Info Media.

Notoatmodjo, S. 2010, Promosi Kesehatan Teori dan Aplikasi, Jakarta : Rineka Cipta

Pendit, B.U, Wulandari. P, Hartato. H. 2006, Ragam Metode Kontrasepsi, Jakarta : Penerbit Buku Kedoteran, EGC. 